\title{
REPORTS
}

\section{Argentine Olympiad in Informatics}

\author{
Agustín Santiago GUTIÉRREZ \\ Universidad de Buenos Aires, FCEN, Argentina \\ e-mail: asgutierrez@dc.uba.ar
}

\begin{abstract}
This article describes Argentina's selection and training process for the International Olympiad in Informatics, to identify and prepare the Argentine team members participating in the international olympiad. Additionally, recently developed online resources that have proved very useful for student preparation are presented.
\end{abstract}

Keywords: olympiads, programming contest, selection, training, grading systems.

\section{Introduction}

In the year 1990, Argentina started to participate in the International Olympiad in Informatics (IOI) (Kalinicenko, 2020). However, the Argentine Olympiad was under a different administration at that time, and it was suspended after the 1994 IOI. Argentina did not participate in the IOI 1995 and 1996 editions. Very few contacts, statistics and records are available from this period.

In 1996, OIA ("Olimpíada Informática Argentina", that is, the Argentine Olympiad in Informatics) was started once again (OIA, 2020c), now based at General San Martín National University (UNSAM) in the Buenos Aires Province. Since then, the olympiad has been running continuously at UNSAM, selecting and sending delegations to IOI every year. OIA is part of a general National Program of Olympiads (Argentina.gob.ar, 2020), in which the Ministry of Education assigns the task of organizing the different Science Olympiads in Argentina to National Universities.

Up to and excluding 2020, Argentina has participated in 28 IOIs, obtaining 3 gold medals (1990, 2003, 2018), 9 silver medals, and 23 bronze medals. 


\section{IOI Selection Process}

\section{General Contest Environment}

In all of OIA contests, each task is graded from 0 to 100 points, similar to IOI.

All contest up to and including year 2013 were run either by manually collecting and testing all the contestants' code at the contest's end, or by using custom OIA Contest Management Software.

From 2014 onwards, CMS (Maggiolo and Mascellani, 2012; Maggiolo et al., 2014) has always been used for the National Contest and the Selection Contest. This has been an enormous improvement in term of Contest Management quality, and has also allowed students to be already familiar with the IOI Contest Environment before actually arriving at IOI.

Except for the Selection Contest (last round), only Batch-type tasks have been used so far in the olympiad.

\section{First round: Jurisdictional Contest}

The Jurisdictional Contest is open to any high-school student in Argentina. It is divided into three levels, based on school-year (counted from first grade, that is, the first year of primary education):

- Level 1: 8th and 9th grade.

- Level 2: 10th and 11th grade.

- Level 3: 12th and 13th grade.

The country is divided by OIA into jurisdictions, a term chosen to encompass at the same time provinces, Buenos Aires City, and regions of large provinces. Each jurisdiction has a Jurisdiction Coordinator appointed by OIA. The country is divided into $25-30$ jurisdictions, with the precise number varying in recent years.

In 2019, the Jurisdictional Contest was coordinated nationally by OIA for the first time (OIA, 2020d). It is now a single contest across the whole country: students gather at schools designated by their jurisdiction's coordinator, and log into an online running CMS server in order to compete.

Previously, the jurisdiction coordinators were in charge of selecting its contestants for the National Contest however they judged appropriate, being required only to present a final list of students of at most 3 per level per jurisdiction. Since 2019, a single national contest is prepared by the national judges (aided by helping judges from the different jurisdictions) and the whole country has to compete using this same contest on the same day of competition. This has been a significant improvement in terms of statistics gathered by OIA about its student base.

The contest has a length of four hours, and consists of four tasks per level. It is the judges intention that the first of the four tasks in each level is very easy: it should take 
experienced, well-prepared contestants in the corresponding levels no more than 5-10 minutes to read and fully solve these tasks. This decision, as well as the total of four tasks, helps in successfully using a single contest throughout the whole country, accommodating large differences in level among the different jurisdictions.

232 students submitted solutions in this round in 2019: 36 in level 1, 104 in level 2, and 92 in level 3.

Top students advance to National Contest. The previous rule of selecting always 3 students per level per jurisdiction has been changed in 2019 (OIA, 2020e; OIA, 2020f). Now, only the best two students (as determined by their scores in this unified round) per level per jurisdiction are selected. Based on the available budget for the National Contest, additional wildcard slots are added for the next best scoring students, regardless of their jurisdiction.

\section{Second Round: National Contest}

This is an onsite contest. All of the students are gathered in the same city, with expenses covered by OIA.

The National Contest is divided into three levels, exactly the same as the Jurisdictional Contest. In the last decade, about 60 to 100 students have partipated in the National Contest each year.

The contest has a duration of four hours, and consists of three tasks per level. After a single contest day, medals are awarded to the top contestants in each level.

Traditionally, exactly three medals per level were given: Gold for the best contestant, silver for the second best, and bronze for the third place. Since 2019, the medal allocation algorithm was changed based on the number $N$ of contestants achieving at least $25 \%$ of the total possible score:

- Gold: $\frac{N}{10}=2 \frac{N}{20}$ medals.

- Silver: $3 \frac{N}{20}$ medals.

- Bronze: $\frac{N}{5}=4 \frac{N}{20} \quad$ medals.

This was done both to allow more medals in cases where many good contestants appear in the same level, and to prevent bronze medals from having extremely low scores. The number of medals in recent years would not have changed much if the rule had been in place, except when these special cases occurred. The jury is allowed to decide on the precise cutoffs in the case of ties and near ties.

The top students in the National Contest are allowed to advance to both the Selection Contest and the Iberoamerican Olympiad in Informatics (CIIC) (OEI, 2020; OIA, 2020a). As stated in OIA rules (OIA, 2020e), the advancing contestants are the top three students of level 1, the top four students of level 2, and the top six students of level 3. The jury is allowed to make additional students advance based on their performance in the National Contest. 


\section{Third Round: Selection Contest}

The final round is the Selection Contest. The goal is for it to be as similar to the IOI contest as possible: that is why it is organized in two days of competition, having a duration of five hours and three tasks per day, and separated by a free day without competition. Traditionally, Batch-type tasks were used exclusively from 2000 to 2015, but in recent years other type of tasks have been included, in alignment with typical IOI tasks types:

- Interactive tasks: The first interactive task ever used in OIA was Iluminando el árbol de Navidad (Lighting up the Christmas Tree), used in 2016 (OIA, 2020b). A total of four interactive tasks have been used in the Selection Contest, exactly one per year:

- Iluminando el árbol de Navidad (2016).

- Encontrando el Tiranic (2017).

- Secuenciando el ADN (2018).

○ Cultivando bacterias (2019).

- Output-Only tasks: The first output-only task ever used in OIA was Contando Subredes (Counting subnetworks), used in 2018 (OIA, 2020b). A second outputonly task, Recuperando distancias (Recovering distances), was used en 2019. These remain the only two output-only tasks to have ever been used, before and excluding 2020.

The top four contestants, by total score after adding together both competition days, are selected for the IOI Team.

Number of Participants

The total number of contestants per round and year for recent editions of the olympiad is shown in Fig. 1.

\section{Student Preparation}

\section{Dedicated Training by OIA}

Once the IOI Team is selected, it is invited to attend an onsite-training, typically lasting about a week. This is an intensive, focused training event where the four students are lectured in different topics during the morning by an instructor, and are given time to solve and code homework problems during the afternoon.

Apart from the onsite training, the team is also in contact with an instructor for remote training up to the time of the IOI itself. This training consists mainly of the assignment of reading material and homework problems by the instructor, as well as asking and answering questions by email or messaging. 


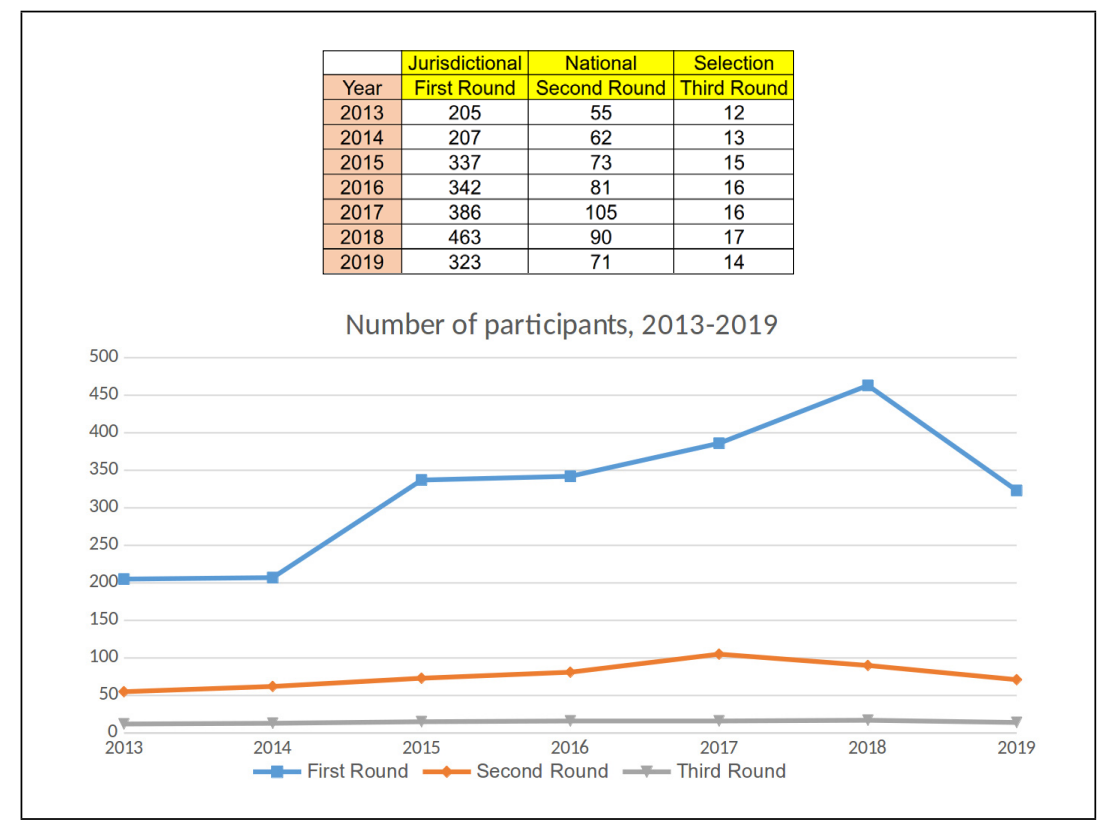

Fig. 1. Number of participants (2013-2019).

\section{OIA Online Resources}

In order to help students and teachers to prepare for the olympiad, OIA has several online resources focused on high school informatics olympiads in Spanish. Except for the webpage itself, all of these resources were launched in 2017, and have already been very well received by teachers and students in Argentina.

- Website: http://www.oia.unsam.edu.ar

- YouTube Channel: (Olimpíada Informática Argentina) http://www . youtube.com/channel/UChUJZDER53wT7VNT_UwCJyw

There is not much video material by OIA yet, but that which has already been published is available via this channel.

- Wiki: http://wiki.oia.unsam.edu.ar

This is a website aimed at providing trusted, high quality reference material about programming competitions in Spanish, mainly focused on high-school level competitions like OIA. It is not an open wiki, but only OIA's instructor's and trusted ex-competitors are allowed to write articles. An important ongoing effort consists in completing and improving this site.

- Forum: http://foro.oia.unsam.edu.ar This official OIA forum has proved quite helpful in creating a sense of online community around OIA.

- Judge (OIAJ): http: //juez . oia . unsam. edu . ar

An online judge dedicated to hosting OIA's problems. It is directly based on cmsocial (GitHub, 2020), the direct sucesor of oii-web (Di Luigi et al., 2016) 
The judge has improved student preparation enormously, as it gives access to an easy to use online judge very similar to the real CMS used during OIA's contests, with an interface and competition tasks in Spanish. Many workshops and training sessions have used OIAJ as its main online judge. Users from various countries in Latin America have used OIAJ as a source of competition problems in Spanish.

\section{OIA Additional Resources}

Booklets ("Solucionarios"): Starting since 2017, an official booklet is published containing solutions and explanations to all the problems used that year in the olympiad $(12+9+6=27$ problems per year). The 2017 booklet was completed and published (OIA, 2020g) in the beginning of 2019. The 2018 booklet was completed in december 2019 , and is expected to be released in early 2020 . The 2019 booklet is being written and is expected to be released sometime during 2020.

- Talks: Since 2014, talks have been given during the National Contest event. These are typically lectures by ex-competitors focused on some competitive programming topic. Also, a lecture for beginners has been given many times, and is quite well received by teachers and students. This is a lecture explaining how to solve simple problems using for loops, how to understand statements, and such fundamental skills.

Many of these talks are filmed and have been published in OIA's Youtube Channel. Most of them have slides available in OIA's webpage (OIA, 2020h).

\section{Future work}

It is motivating to see that many of these new resources launched by OIA in recent years have been very well received by teachers and students. There is however a lot of room for improvement. Some important goals for the coming years are listed:

- Upload to OIAJ all problems having a statement published in OIA's webpage so that they can be submitted there.

- Improve the wiki so that it covers material easily available in English (C.P. Handbook (Laaksonen, 2017), cp-algorithms.com, etc)

- Increase participation in the forum.

- Make it easier to start participating. Some ideas: visual tasks, visual programming, paper-and-pencil exams.

- Increase the total number of participanting students and schools.

- Create OIA training camps, and more generally, increase the availability of training courses. 


\section{References}

GitHub (2020). CMSocial. A web application that builds a social coding platform upon cms. https://github.com/algorithm-ninja/cmsocial. Accessed: 2020-02-08.

Argentina.gob.ar (2020). Ministry of Education. National Olympics Program. https://www.argentina.gob.ar/educacion/programa-nacional-de-olimpiadas. Accessed: 2020-01-18.

OIA* (2020a). CIIC : Competencia Iberoamericana de Informática y Computación. http://www .oia. unsam. edu .ar/ciic-reglamento. Accessed: 2020-01-18.

OIA (2020b). Competition Tasks.

http://www.oia.unsam.edu.ar/problemas-categoria-programacion/\#seleccion. Accessed: 2020-01-24.

OIA (2020c). History. http: //www . oia. unsam.edu. ar/antecedentes. Accessed: 2020-01-18.

OIA (2020d). Nationally Coordinated Jurisdictional Contest. http://www.oia.unsam.edu.ar/instancia-jurisdiccional-oia-2019. Accessed: 2020-01-18.

OIA (2020e). Rules. http://www.oia.unsam.edu.ar/reglamento. Accessed: 2020-01-18.

OIA (2020f). Rules - Structure. http: //www . oia. unsam. edu . ar/estructura. Accessed: 2020-01-18.

OIA (2020g). Solucionario OIA (problemas 2017). http://www.oia.unsam.edu.ar/oia-programacion/. Accessed: 2020-02-08.

OIA (2020h). Talks. http: //www. oia.unsam.edu. ar/charlas/. Accessed: 2020-02-08.

OEI (2020). Organization of iberoam erican states - ciic. https://www.oei.es/historico/ciic.htm. Accessed: 2020-01-18.

Di Luigi, W., Farina, G., Laura, L., Nanni, U., Temperini, M., Versari, L. (2016). oii-web: an interactive online programming contest training system. Olympiads in Informatics, 10, 207-222.

Kalinicenko, E. (2020). International Olympiad in Informatics - statistics. http://stats . ioinformatics . org/results/ARG. Accessed: 2020-01-18.

Laaksonen, A. Competitive programmer's handbook. 2017.

Maggiolo, S., Mascellani, G. (2012). Introducing cms: A contest management system. Olympiads in Informatics, 6.

Maggiolo, S., Mascellani, G., Wehrstedt, L. (2014). Cms: a growing grading system. Olympiads in Informatics, 8 .

\footnotetext{
* OIA-ArgentineComputer Olympiad
} 


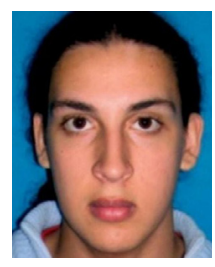

A.S. Gutiérrez. MS in Computer Science at FCEN-UBA (Buenos Aires University). Two times IOI contestant (2006 and 2007), winning a Silver Medal in 2007. Two times World Finalist and Latin American Champion at ICPC (2009 and 2011), and seven times world finalist as a coach (2010, 2013, 2014, 2015, 2016, 2017 and 2020), coaching the Latin American Champion team in 2015. Actively involved in helping with the organization and running of the Argentine Olympiad in Informatics (OIA) contests since 2011. Since 2015, official National Jury and IOI team trainer at OIA, and Deputy Leader of Argentina at IOI. Organizer in 2019 and 2020 of the Iberoamerican Olympiad in Informatics (CIIC), a regional contest spanning Latin America, Spain and Portugal. More than ten times organizer and lecturer at more than five different ICPC Training Camps in Argentina and other Latin American countries. Teaching fellow from 2013 to 2018 at FCEN-UBA, teaching the course "Algorithms and Data Structures 3" (Algorithmic techniques and graphs). More than five year experience as a software engineer developing customized search engines and algorithms for an online retail business at Brightsector Algorithms. Assisted Topcoder as local organizer of the TCO 2018 Argentina Regional Event. Native Spanish speaker, fluent in English, studying Russian (approaching A2 level). 